\title{
WATER BODY DETECTION FROM TANDEM-X DATA: CONCEPT AND FIRST EVALUATION OF AN ACCURATE WATER INDICATION MASK
}

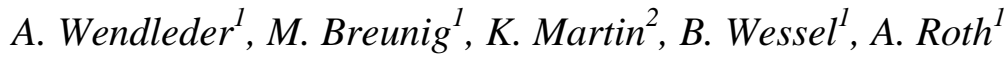 \\ ${ }^{1}$ German Aerospace Center (DLR), Oberpfaffenhofen, 82234 Wessling, Germany, \\ Tel. +498153283439 \\ [Anna.Wendleder, Markus.Breunig, Birgit.Wessel, Achim.Roth]@dlr.de \\ ${ }^{2}$ Company for Remote Sensing and Environmental Research (SLU), 81243 Munich, Germany \\ [klaus.martin@slu-web.de]
}

\begin{abstract}
Additionally to the main product of the TanDEM-X mission - the global Digital Elevation Model (DEM) - a global water body mask will be produced. The main goal of this water mask is to deliver an information layer to support a subsequent DEM editing process. It is derived from the SAR amplitude and the single pass coherence. In this paper, the concept of the global water body detection is explained and a first evaluation of the single coverage water body detection is presented.
\end{abstract}

Index Terms-TanDEM-X DEM, water, extraction, detection

\section{INTRODUCTION}

Usually water surfaces shall be flat and smooth in a digital elevation model and should not poke out of the surrounding landscape. An interferometric derivation of elevation information fulfills these requirements whenever a water surface is completely frozen or the along track baseline is zero during the acquisition. Occasionally TanDEM-X data are acquired under those conditions. Mostly however a small but noticeable along track baseline exists. Structural changes of the water surface within this small time frame cause the backscattered signals to de-correlate and a noisy appearance of the corresponding DEM values. In order to support a DEM editing a complementary data set is provided with the interferometric DEM, the so called potential water body mask.

The water body detection of TanDEM-X runs completely data-driven within the DEM Preparation Processor of the 'DEM Mosaicking and Calibration Processor' (MCP) [1,2] and is based on Raw DEM level, i.e. on interferometric scenes with a size of $30 \times 50 \mathrm{~km}$. After the first year of global acquisition, it is planned to merge all Raw DEM to the intermediate DEM, herein, the WAM will also be merged to a complete global product.
In this paper we focus on the detection of water bodies on Raw DEM level. The challenge is the processing of a large amount of data in a very tight schedule. Usually 400 up to 800 Raw DEM are processed per day providing a maximum computing time of 3 minutes per product for the water body detection. Nevertheless the technique applied needs to account for the different appearances of water bodies worldwide like ponds, arctic sea, rough oceans, frozen and salt lakes or small rivers.

\section{CONCEPT OF WATER BODY DETECTION}

Currently sophisticated methods in SAR imagery processing for water body detection are using parametric and geometric active contour models [3, 4] and texture measures. But these are not efficient enough to be applied for near-real-time image processing and cannot be applied fully automatically [5]. The only possibility to keep up with the amount of daily incoming data during the TanDEM-X mission is to process the data fully automatically and to use a less timeconsuming threshold method.

At the beginning of the TanDEM-X mission, the water body detection was designed only for amplitude images. But during the commissioning phase it turned out that in most cases water is incoherent for common along-track distances (200-500m) and consequently, the coherence image can be perfectly used as an additional information layer to achieve more reliable results in the detection of water bodies.

The water body detection contains five main steps: (1) exclusion of non-water zones, (2) median filter, (3) threshold method, (4) a chain code, and (5) a fusion (see Figure 1).

(1) At the beginning of the algorithm, additional information layers are used as well. One is the SRTM WAM (in an edited version) which is used as reference data to control the water body mask derived of TanDEM-X. Another one is the MODIS/Terra Land Cover Types dataset (2001-2004) which is available as a global $1 \mathrm{~km}$ raster 
dataset (MOD12Q1) or global $0.05^{\circ}$ raster dataset (MOD12C1) [6]. We use specific land cover classes "Barren or Sparsely Vegetated" and "Snow and Ice". Both datasets are used to exclude desert and Polar Regions from water detection because of a significant rate of misclassifications due to the dark appearance of arid sand dunes or the coherent frozen and icy polar water bodies. In both cases water body detection is neglected because of a) error respectively b) frozen water bodies that do not have to be flattened afterwards. Moreover, as a third information layer a slope mask based on the SRTM DEM [7] is calculated within $60^{\circ} \mathrm{N}$ and $60^{\circ} \mathrm{S}$ with the SRTM DEM being available. Outside this area, this approach is not performed because of missing accurate DEM reference data. With this supplementary slope layer it is possible to eliminate areas covered with radar shadow in steep terrain which could misleadingly be classified as water. Moreover, a pre-calculated flag mask delivered by the Integrated TanDEM-X Processor (ITP) is used during the threshold method to exclude misclassifications due to radar shadow or layover.

(2) The median filter is applied separately both to the amplitude and the coherence image to reduce noise and minimize misclassification errors.

(3) In this step the thresholds are applied. To get the best result for water body detection, the threshold value should be adapted for every Raw DEM individually. But the effort for such an amount of Raw DEM would be too large. The only possibility is to minimize the manual operating interaction by using fix threshold values. During commissioning phase, it turned out that two amplitude threshold values provide good results. The first threshold shall represent a reliable classification and the second threshold a potential classification. The thresholds were determined empirically, the first threshold value is 0.0145296 in beta nought, i.e. around 37 in digital number, the second threshold value is 0.0326917 in beta nought, i.e. around 60 in digital number. For the coherence image only one threshold value is used that was empirically determined, too. This value is 0.23 . All pixels whose value is below the threshold are consequently classified as water.

(4) After the threshold processing of both amplitude and coherence images, a so-called chain code [8] is applied. The chain code bases on the connected component and circles every single water body to calculate its area. Water bodies with a size smaller than 1 hectare will be eliminated. Finally, three intermediate water body layers are resulting.

(5) In a fusion step, the three water body layers are merged together to the WAM product. A sophisticated rule set of logics is evaluating the resulting output. Thereby, the decision is made if the water masks derived from coherence and amplitude thresholds are suitable for the generation of our WAM product.

\section{QUALITY ASSESSMENT OF SINGLE WATER MASK}

Since water bodies in SAR data are occurring in a wide range of natural appearance due to size, pattern, and physical impacts, the WAM algorithm needs to handle different representations for generating an accurate water body mask. Therefore a validation of the method, its thresholds, and its accuracy is an important step.

A comparison between the water masks derived of TanDEM-X and reference data show the quality of our results.

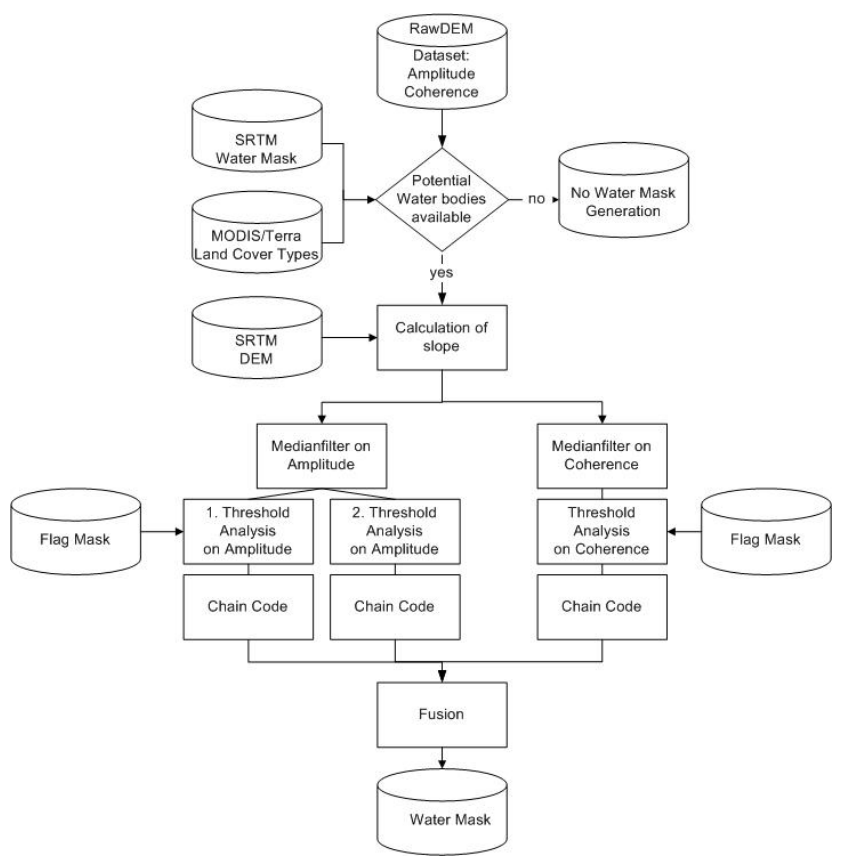

Figure 1: Routines for water body detection and WAM production workflow.

\subsection{Test site}

As an appropriate test site a temporarily tide-effected section of the river Elbe near Hamburg, Germany, was chosen. The acquisition had been performed with the bistatic operational TanDEM-X mode on January 27, 2011 with an incidence angle of $43.4^{\circ}$ to $45.7^{\circ}$ (see Figure 2). Next to the large upper stream course of the river Elbe, there are some other smaller water bodies like the NordOstsee Channel, river Oste and river Stoer. All water bodies are appearing smooth and dark without any disturbances caused by wind effects, snow and ice coverage or others. Figure 3 and 4 show the WAM derived of the amplitude and the coherence image overlaid with SRTM WAM. 


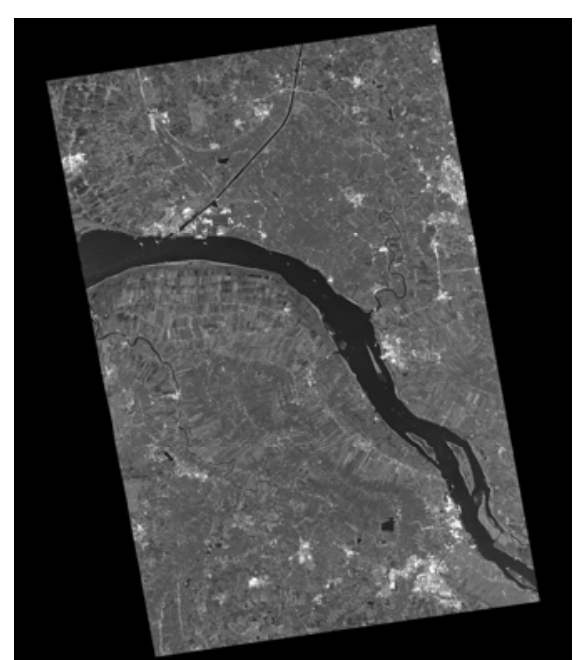

Figure 2: Amplitude image of river Elbe near Hamburg, Germany, acquired on January 27, 2011.

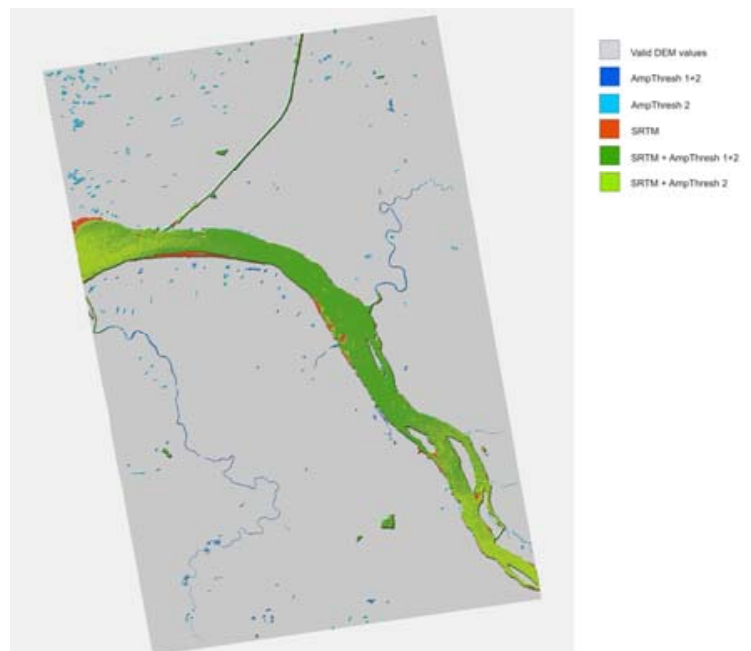

Figure 3: Water bodies detected by amplitude thresholds.

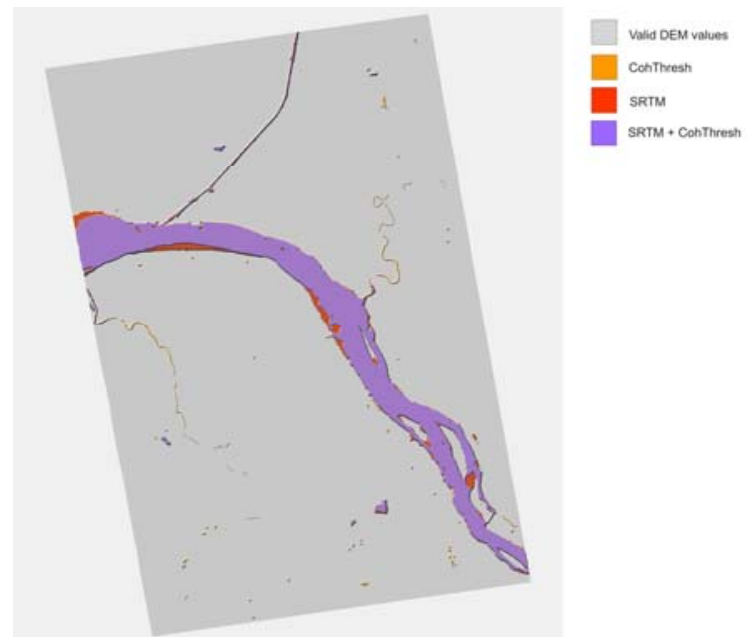

Figure 4: Water bodies detected by coherence.
As reference data for the accuracy assessment, we used a reference vector layer data of digital landscape models (DLM) taken from the Authoritative TopographicCartographic Information System (ATKIS) provided by the Federal Agency for Cartography and Geodesy (BKG). The used layer contains up-to-date information about spatial location, geometric type and descriptive attributes about all water bodies like river, ocean, canal, inland lake, lake and tidal flat.

\subsection{Evaluation}

In a first step, WAM and the reference data have been intersected using GIS. The result of the amplitude thresholds displays a good correlation (Figure 3): the river Elbe is exactly classified, also thin rivers with its meanders and the small lakes are classified continuously. On the other hand some agriculture areas are misclassified as water, because they appear dark as well. Also, ATKIS declares some agricultural areas in the south of the river Elbe being temporally flooded and consequently they are supposed to be classified correctly. Since the coverage of water varies temporary, it is not easy to decide if water bodies are misclassified or not. The coherence-derived water mask reflects exactly the river Elbe, the thin rivers and the small lakes are captured, too. However, the result is not as rich in detail as the result of the amplitude image. The course of the thin rivers is visible but it is not continuous. Moreover, it has to be stated that only few lakes are classified while on the other side agricultural areas are not misclassified like in the amplitude-derived water mask. Another temporary variability is the mud flat along the river Elbe. In our scene, the mud flat is not covered with water and hence not classified as water neither in the amplitude-derived water mask nor in the coherence-derived water mask. However ATKIS and SRTM WAM display water extensions in these regions.

In a next step, a quantitative accuracy assessment has been performed by regarding completeness and correctness separately for the water body mask derived of the amplitude and the coherence images (see Table 1). Completeness is defined as the percentage of the extracted data which lies within the reference data:

$$
\text { completeness }=\frac{\text { area of extraction within reference }}{\text { area of reference }}
$$

The correctness represents the percentage of correctly extracted water areas, i.e., the percentage of the extracted data lying within the reference area:

$$
\text { correctness }=\frac{\text { area of extraction within reference }}{\text { area of extraction }}
$$

In the case of the amplitude-derived WAM the completeness is $86.9 \%$ and the correctness is $92.6 \%$ for. 
That means that only $86.9 \%$ of the total water area of ATKIS is classified. The missing $13.1 \%$ bases on the mud flat which is not classified as water. The probability that the pixel is correctly classified is $92.6 \%$. The correctness equals not $100 \%$, because a lot of agriculture areas are misclassified. This comparison is executed with all water bodies in ATKIS. The second comparison is only carried with water bodies with a size greater than 1 hectare according to the product specifications. Then, completeness increased to $88.1 \%$ because small water bodies are eliminated in the reference data. The completeness of the coherence-derived WAM is $79.8 \%$ and the correctness is $98.7 \%$. The missing $20.1 \%$ of completeness is due to the fact that the thin rivers are not represented continuously and that the mud flat is not classified. Therefore, correctness is very high. The comparison of reference data and water bodies (larger than one hectare) increases completeness to $80.9 \%$. This value has almost not changed because the coherence-derived water mask did not misclassify agricultural areas.

\begin{tabular}{|l|l|l|}
\hline Reference & Completeness & Correctness \\
\hline & \multicolumn{2}{|c|}{ Amplitude } \\
\hline ATKIS & $86.9 \%$ & $92.6 \%$ \\
\hline ATKIS without 1ha & $88.1 \%$ & $92.5 \%$ \\
\hline & \multicolumn{2}{|c|}{ Coherence } \\
\hline ATKIS & $79.8 \%$ & $98.7 \%$ \\
\hline ATKIS without 1ha & $80.9 \%$ & $98.7 \%$ \\
\hline
\end{tabular}

Table 1 Evaluation results of the Elbe test site regarding two reference data sets

\subsection{Discussion}

Within this work, two different data sources for water body indication have been presented. On one side, the achieved accuracy of the coherence-derived water mask states clearly that coherence can be used as a significant and robust indicator for the detection of water bodies in SAR data although a loss of details of small scale water bodies is observable. On the other side, the amplitude-derived water mask represents very well the smooth course of a river with all its details. Nevertheless, its quality is seriously downgraded due to already above mentioned effects appearing quite regular in SAR data. Therefore, our chosen approach of generating a global water indication mask within the TanDEM-X mission is based on using both WAM layers derived by amplitude and coherence of both first and second TanDEM-X acquisition and to use all possible information for the generation of the final WAM product.

\section{CONCLUSION}

With respect to the limited computation time, a rather simple threshold method has been chosen for the TanDEM$\mathrm{X}$ water body detection. To handle the complexity of the appearance of water in SAR data we set different thresholds. The amplitude data are suited to detect most of the details of open water therefore the parameters are more relaxed to achieve a good completeness. In return, the threshold for the coherence is set stronger to deliver more reliable resp. correct results but less complete. In combination, we obtain a maximum of correct and complete water body masks.

Our ongoing work and research focuses on (1) the accuracy of our water body detection algorithm for different climatic zones and (2) the beginning of mosaicking of different WAM layers to an intermediate and final WAM product.

\section{ACKNOWLEDGEMENT}

The TanDEM-X project is partly funded by the German Federal Ministry for Economics and Technology (50 EE 1035).

\section{REFERENCES}

[1] Huber, M., A. Gruber, B. Wessel, M. Breunig \& A. Wendleder, 2010. Validation of the Tie-Points Concepts by the DEM Adjustment Approach of TanDEM-X. Proceedings of the IEEE International Geoscience and Remote Sensing Symposium (IGARSS 2010), July 25-30 2010, Honolulu, Hawaii, USA, pp. 2644-2647.

[2] Wessel, B., U. Marschalk, A. Gruber, M. Huber, T. Hahmann \& A. Roth, 2008. Design of the DEM Mosaicking and Calibration Processor for TanDEM-X. Proceedings of the $7^{\text {th }}$ European Conference on Synthetic Aperture Radar (EUSAR 2008), June 2-5 2008, Friedrichshafen, Germany, pp. 111-114.

[3] Hamarneh, G., A. Chodorowski \& T. Gustavsson, 2000. Active Contour Models: Application to Oral Lesion Detection. Color Images. IEEE International Conference on Systems, Man, and Cybernetics, Vol. 4, pp. 2458-2463.

[4] Wasilewski, M., 2005. Active Contours using Level Sets for Medical Image Segmentation, Matlab Codes.

http://www.postulate.org/segmentation.php.

[5] Hahmann, T. \& B. Wessel, 2010. Surface Water Body Detection in High-Resolution TerraSAR-X Data using Active Contour Models. Proceedings of the $8^{\text {th }}$ European Conference on Synthetic Aperture Radar (EUSAR 2010), June 7-10 2010, Aachen, Deutschland, pp. 897-900.

[6] MODIS, 2006. http://edcdaac.usgs.gov/modis/mod12q1v4.asp

[7] SRTM, 2010. http://srtm.usgs.gov/

[8] Miszalok, V., 2007. Computer Vision, Chapter 2: Chain Code. http://www.miszalok.de/Lectures/L08_ComputerVision/CrackCod e/CrackCode d.pdf 